\title{
Challenging Stress and Scientific Research Performance of Faculties in China
}

\author{
Yingchuan ZHAO, Zhonglin ZHOU, Xiao PEI \\ Yangtze University, Jingzhou, China \\ $\{29682340,364237610,308089209\}$ @qq.com
}

\begin{abstract}
The study adopts random sampling to investigate the quantity and quality of 1706 teachers' published articles in the six years before and after the implementation of the performance appraisal system in four research-teaching universities and teaching universities in a certain province in China. The researching findings show that performance appraisal gives rise to a challenging stress for research-teaching university and teaching universities teachers, which contributes to improving teachers' scientific research productivity and influence; influences of performance appraisal on different groups of teachers are significantly different. As for professors and associate professors, performance appraisal has significant influence on the quality of their scientific research but insignificant influence on the quantity. As for lecturers, it has significant influence on both quality and quantity of their scientific research. As for teaching assistants, it has no significant influence on both quality and quantity of their scientific research.
\end{abstract}

Keywords: Performance Appraisal System, Challenging Stress, Scientific Research Performance.

\section{Introduction and research question}

At the end of 2016, China has 2596 colleges and universities. Among them, 813 are the public universities offering degree programs, and 1783 are higher vocational colleges and other institutions. Comparatively, the quality of public universities is the higher than the other two kinds. These public universities include 39 research universities and 774 research-teaching or teaching universities. In 2016, the number of graduate students has reached 7.56 million which by all means makes China the biggest higher education country in the world. However, in terms of quality, China has a distance from a powerful country in higher education in the world. Hence, China has proposed the " 985 project" and " 211 project" which aims to support some universities to develop into world-class universities or a high-level universities by concentrating limited resources.

Faculty is the most important human capital in universities. That who has the highest quality teachers is who can take a lead in the fierce competition. That who can innovate teacher' creativities is who can improve the academic productivities of the university. As a matter of result, on the one hand, Chinese universities enforce the 
attractive to the talent. On the other hand, universities have been establishing their performance appraisal systems, and the results of evaluation are the important basis for teachers' salary and reward.

However, after the implementation, the system was criticized and questioned by the majority of scholars. Some researchers pointed out that the performance appraisal which started in the business circles had been an obstacle to enterprise management, and the performance doctrine made Chinese enterprises get into trouble [2]. As academic organizations, universities should not implement the performance appraisal. According to the fact that the number of unqualified faculty accounted for only $1 \%$ to $2 \%$ of the total number after an appraisal cycle, some scholars drew the conclusion that at present, performance appraisal system of researching universities or researching and teaching universities in China did not achieve the function of screening and stimulating [12].

The existing literatures on the validity of the teacher performance appraisal system in universities mainly take research universities as research objects, other universities such as research-teaching universities and teaching universities are rarely involved. Seen from one's intuitive feelings, teachers from research universities have higher human and social capital and stronger academic self-discipline. The academic interest and the strong academic atmosphere are sufficient to enable them to pursue scholarly research as a career. There is no need to be restrained and stimulated by the appraisal system. However, most teachers in research-teaching universities and teaching universities regard academic research a vocation. Their initiative is not strong enough by the stimulation of internal awareness, which needs appropriate stress by an external system. So, is this feeling a reality? It needs empirical study.

The aim of the thesis is to study the validity of the teacher performance appraisal system in research-teaching universities and teaching universities in China. The present performance appraisal system is implemented according to the "top down" model at the same time taking the province as a unit, which means the time of implementing the system in universities of each province is the same while the starting point of time is different. The environment of the system is of great significance to the implementation influence, and "time" is an important environmental variable. Therefore, the thesis chooses four universities in China's central province as the research object and explores the validity of the performance appraisal system by analyzing the difference in academic productivity before and after the implementation of the system.

\section{Research Hypotheses}

A system has the function of punishment, so does the teacher performance appraisal system in universities. Punishment rules are bound to bring some stress to teachers and thus influence their academic life.

As early as the mid-twentieth century, Selye divided stress into eustress and distress according to the stress levels. Then, Lazarue and Folkman thought that stress 
is not situational stimulation, individual characteristics or reflection, but interactions between situational requirements and abilities of handling the requirements. When the individual thinks that the requirements are beyond ones' ability, one will have the feeling of threat; when the requirements are within ones' ability, one will have the feeling of challenge [5, 6]. Cavanaugh put forward a two-dimension structural model of challenging-obstacle stress source on the basis of previous studies. The challenging stress source refers to the stress source which brings positive influence to the enterprise and the staff, including the following requirements, such as heavy workload, time stress, work scope and high responsibility. It can bring stress as well as growth, returns and benefits in the future, and it can also stimulate the sense of achievement. Therefore, it can bring positive influence. The obstacle stress source refers to the stress source which brings negative influence to the enterprise and the staff, including the following requirements, such as policies, complex and draggy official procedures of the organization, ambiguous roles and safety concerns. It can hinder an individual's growth and achievement of goals and bring negative influence [3].

In this study, we assume that the teacher performance appraisal system in universities is a challenging stress source whose requirements for teachers are within their abilities. Moreover, all costs teachers paid to achieve appraisal tasks will get higher returns. This kind of positive influence will promote the increase in the quantity of scientific research.

Based on the above analysis, Hypothesis 1 has been formulated as follows:

Hypothesis 1: The teacher performance appraisal system in universities contributes to increasing the quantity of scientific research.

Academic productivity includes not only the quantity of teachers' scientific research, but also its quality. Some researchers have pointed out that the teacher performance appraisal system forces teachers to struggle hard to complete tasks, which will easily lead to quick success as well as the pursuit of academic short-term effect and they tend to choose "hot" topics as research objects, and pay more attention to the quantity of published articles instead of the quality, and some of them even divide a complete academic research thesis into several papers to publish [10]. Under the stress of annual appraisal of scientific research tasks which must be achieved every year, teachers can only choose some short, steady, and fast projects. For those projects that need long-term basic research, teachers may want to research, but this kind of research seems to be a kind of "luxury" under such appraisal system, which teachers cannot afford [15]. This kind of fast-food research just "turns white paper into black paper", or even "white paper into waste paper". They have subject awareness but no problem awareness, fund awareness but no academic awareness, quantity awareness but no quality awareness [4].

Based on the above analysis, Hypothesis 2 is put forward as follows:

Hypothesis 2: The teacher performance appraisal system in universities is adverse to increasing the quality of scientific research.

How does an individual react when facing stress. In their Stress Handling Theory Folkman and Lazarus claim that individual will start a cognitive appraisal in the process of interactions with surroundings. In the primary appraisal process, one will 
appraise whether the events, situations or problems are relevant to oneself, whether they are benign, positive or stressed [5]. If they have nothing to do with oneself, so do they to the whole staff; If the events, situations or problems are beneficial and positive, one will make good appraisal, such as getting a promotion opportunity; if they are threatening or harmful, one will make a bad appraisal, such as conflicting with the responsible person or being fired (Shi Yu, Liu Cong, Liu Xiaoqian, Shi Kan,2009). One will take further measures to deal with the events, situations or problems according to the primary appraisal. The measures include emotional handling strategies and problem handling strategies, which will influence the individual's mood or behavior. If one thinks the events have nothing to do with him, he will ignore them; if he thinks they are beneficial and within his ability and can be solved through efforts, he will challenge them with passion; if he thinks they are beneficial but beyond his ability, and no matter how hard he works, he still cannot relieve stress, or if the events themselves are obstructive, he will be evasive and do nothing [7].

Teachers in universities are divided into professors, associate professors, lecturers and teaching assistants according to the titles. Theoretically speaking, they have different human capital, social capital and achievement feeling for their job, and their cognitive appraisal of the stress source is different with respect to the performance appraisal system, thus their handling of and reaction to stress are different accordingly. Therefore, the study has put forward its third hypothesis as below:

Hypothesis 3: The teacher performance appraisal system in universities has different stimulating functions to professors, associate professors, lecturers and teaching assistants.

\section{$3 \quad$ Research Methods and Results}

\subsection{Research Sample}

The study chooses the teachers in four research-teaching universities and teaching universities in one of China's central provinces as the research object. In the four universities, two of them are located in the capital city and the other two are located in local cities. The study adopts random sampling to select 1832 teachers in the four universities and then rules out 126 teachers whose teaching time is less than six years, and finally the total number of teachers in the sample is 1706 . Their demographic characteristics are: 1075 male teachers, 631 female teachers; 261 professors, 567 associate professors, 850 lecturers, 28 teaching assistants; 361 Doctors, 1111 Masters, 234 Bachelors and others.

\subsection{Definition of the Variable}

The functions of university teachers include teaching, scientific research and social service, which are involved in their appraisal. According to the interviews the author had with the research subjects, the main appraisal index of teaching is "teaching 
hours" and there is no regular appraisal index for teaching quality in the four universities. The appraisal of scientific research mainly involves quantity and quality of research projects, published articles, monographs, and patents. The appraisal of social service mainly includes attending academic conferences, department activities and so on. There are universities that do not take social service into the appraisal system. We also know from the interviews that after the Ministry of Education issued its Several Opinions on Improving the Quality of Higher Education in an All-round Way in 2012, many universities have taken numerous measures to improve the quality of talents training, including quickening the pace of introducing teachers and reducing the student-teacher ratio. Increasing the number of teachers naturally reduces the number of teaching hours, and this kind of change is far away from the expected result of the performance appraisal system. In other words, the performance appraisal system does not have much influence on teaching. At the same time, Yin Jingong and Wang Yingluo's research findings show that performance appraisal of teaching and scientific research can be replaced to a certain extent [11]. Therefore, the study just takes scientific research performance as the dependent variable to test the validity of the teacher performance appraisal system in universities.

The indexes for measuring scientific research performance include published articles, projects, patents and monographs. According to the general "Publish or Perish" rule in American academia, the direct manifestation of teachers' scientific research performance in universities is the quality and quantity of their published articles. In the study, when collecting and investigating the scientific research data on the research subjects, the author directly selects the articles published three years (2009, 2010 and 2011) before and three years (2012, 2013 and 2014) after the establishment of the performance appraisal system, including all papers published with the subjects as the first author in SCI, SSCI, H\&ACI journals, domestic core journals and common journals. In analyzing the quality of the papers, those published in SCI, SSCI, H\&ACI and domestic core journals are regarded as high-quality papers, and those published in common journals are regarded as common-quality ones. The demarcation of core journals and common journals is based on the periodicals directory published annually by the Peking University.

\subsection{Research Results}

The study adopts SPSS to analyze data, the results are as follows:

First, the number of articles increases significantly.

According to the statistics, before the implementation of the performance appraisal system, the average number of teachers' published articles is 2.57 in three years; after that, it is 2.95 , which increases by 0.374 with a significant difference $(\mathrm{t}=3.637, \mathrm{P}<$ $0.01)$. So Hypothesis 1 has been verified that the performance appraisal system in universities contributes to increasing the quantity of scientific research. 
Table 1. Difference-test of quantity of teachers' articles before \& after the implementation of the appraisal system $(\mathrm{N}=1706)$

\begin{tabular}{lclclcc}
\hline & $\begin{array}{l}\text { Mean } \\
\text { Value }\end{array}$ & $\begin{array}{l}\text { Standard } \\
\text { Deviation }\end{array}$ & SE Mean & $\mathrm{T}$ & $\mathrm{df}$ & $\begin{array}{l}\text { Significance } \\
\text { (bilateral) }\end{array}$ \\
\hline after - before & .374 & 4.247 & .103 & 3.637 & 1705 & .000 \\
\hline
\end{tabular}

Second, the quality of articles improves significantly.

Before the implementation of the performance appraisal system, the average number of teachers' published articles in core journals is 0.79 in three years. After that, it is 1.20 , which increases by 0.41 with a significant difference $(\mathrm{t}=7.402, \mathrm{P}<0.01)$. So Hypothesis 2 has been rejected, thus indicating that the performance appraisal system forces teachers to publish high-quality articles.

Table 2. Difference-test of quality of teachers' articles before and after the implementation of the appraisal system $(\mathrm{N}=1706)$

\begin{tabular}{lllccrl}
\hline & $\begin{array}{c}\text { Mean } \\
\text { Value }\end{array}$ & $\begin{array}{c}\text { Standard } \\
\text { Deviation }\end{array}$ & $\begin{array}{r}\text { SE } \\
\text { Mean }\end{array}$ & t & df & $\begin{array}{l}\text { Significance } \\
\text { (bilateral) }\end{array}$ \\
\hline after - before & .410 & 2.286 & .055 & 7.402 & 1705 & .000 \\
\hline
\end{tabular}

Third, the changing tendency of the quantity and quality is different with respect to the scientific research of teachers with different titles.

To explore the differences in the quantity and quality of articles of teachers with different titles after the implementation of performance appraisal system, the thesis firstly tests the homogeneity variance of the quantity and quality of teachers' articles three years after the implementation of the system, which shows the difference is significant $(\mathrm{F}=17.488, \mathrm{P}<0.01)$ in the number of articles published by professors, associate professors, lecturers and teaching assistants. At the same time, the difference in the number of articles published in core journals is also significant $(\mathrm{F}=17.488, \mathrm{P}<0.01)$.

Table 3. Difference-tests of quantity and quality of articles published by teachers with different titles after the implementation of the system $(\mathrm{N}=1706)$

\begin{tabular}{cccccc}
\hline & Square Sum & $d f$ & $\begin{array}{c}\text { Mean } \\
\text { Square }\end{array}$ & $F$ & Significance \\
\hline Quantity : & & & & & \\
Interdisciplinary & 793.216 & 3 & 264.405 & 17.488 & .000 \\
$\quad$ Interclass & 25732.930 & 1702 & 15.119 & & \\
$\quad$ Sum & 26526.146 & 1705 & & & \\
Quality : & & & & & \\
Interdisciplinary & 359.592 & 3 & 119.864 & 22.1 & .000
\end{tabular}




\begin{tabular}{crrr} 
Interclass & 9218.045 & 1702 & 5.416 \\
Sum & 9577.637 & 1705 & \\
\hline
\end{tabular}

The homogeneity variance test just shows that there is a significant difference between the quantity and quality of articles of teachers with different titles after the implementation of the system. What influence the performance appraisal system has on professors, associate professors, lecturers and teaching assistants can be seen from Table 4: as for professors, the number of their articles published before and after the implementation of the system does not increase significantly ( $\mathrm{t}=1.080(\mathrm{P}>0.05)$, but the number of their articles published in core journals has a significant difference $(\mathrm{t}=3.637, \mathrm{P}<0.01)$. So does the number of associate professors' articles, with no significant difference in the number of articles $(t=1, P>0.05)$ and with a significant difference in the number of articles published in core journals $(\mathrm{t}=2.414, \mathrm{P}<0.05)$. Of the four kinds of teachers, the number and quality of lecturers' articles have the same changing tendency, and the difference in the number of articles is significant $(\mathrm{t}=5.649, \mathrm{P}<0.01)$, and the same goes with their articles published in core journals $(\mathrm{t}=8.120, \mathrm{P}<0.01)$. On the contrary, the difference in the number of teaching assistants' articles is not significant $(\mathrm{t}=0.411(\mathrm{P}>0.05)$, so does the number of their articles published in core journals $(t=0.486(P>0.05)$. Thus, Hypothesis 3 has been verified.

Table 4. Difference-tests of quantity and quality of articles published by teachers with different titles before and after the implementation of the system $(\mathrm{N}=1706)$

\begin{tabular}{|c|c|c|c|c|c|c|}
\hline & $\begin{array}{l}\text { Mean } \\
\text { Value }\end{array}$ & $\begin{array}{c}\text { Standard } \\
\text { Deviation }\end{array}$ & SE Mean & $t$ & $d f$ & $\begin{array}{r}\text { Significance } \\
\text { (bilateral) }\end{array}$ \\
\hline \multicolumn{7}{|l|}{ Professors } \\
\hline after - before(quantity) & 3.75 & 5.619 & .348 & 1.080 & 260 & .281 \\
\hline after - before(quality) & .479 & 3.240 & .201 & 2.388 & 260 & .018 \\
\hline \multicolumn{7}{|l|}{ Associate professors : } \\
\hline after - before(quantity) & .173 & 4.116 & .173 & 1 & 566 & .318 \\
\hline after - before(quality) & .226 & 2.323 & .098 & 2.414 & 566 & .021 \\
\hline \multicolumn{7}{|l|}{ Lecturers : } \\
\hline after - before(quantity) & .746 & 3.850 & .132 & 5.649 & 849 & .000 \\
\hline after - before(quality) & .528 & 1.897 & .065 & 8.120 & 849 & .000 \\
\hline \multicolumn{7}{|l|}{ Teaching assistants : } \\
\hline after - before(quantity) & .143 & 1.840 & .348 & .411 & 27 & .684 \\
\hline after-before(quality) & -.107 & 1.166 & -.220 & .486 & 27 & .631 \\
\hline
\end{tabular}




\section{$4 \quad$ Analysis and Discussion}

Firstly, the performance appraisal system improves the quantity and quality of scientific researches. According to "cognitive interaction theory", the performance appraisal system is an external stimulation for teachers, and they will make a primary cognitive appraisal of the stimulation, such as its meaning and influence. When implementation of the system is directly related to their survival, they will make a cognitive appraisal again, that is, whether their ability can meet the requirements of the system; if they can, they will have the impetus to face the challenge and work hard [5]. As has been introduced above, the performance appraisal system follows the reform path of top-down with a strong mandatory, which is significant to teachers. It is not only directly related to their salary level and decides their quality of life, but also to the post employment and whether they can keep the job. Human behavior is the result of the comparison of cost and benefit. Before the implementation of the system, universities implement an identity management. Once a person becomes a teacher, he or she will be a teacher all their life. In addition, the salary of teachers is average. Therefore, seen from the perspective of survival rather than sense of academic achievement, it is of little benefit for teachers to engage in scientific research. At the same time, it needs high economic cost and time cost, that is, the costs of scientific research are much higher than benefits, which makes them lack motivation to engage in scientific research. After the implementation of the system, universities implement a post management on the basis of performance, and the salary of teachers differs a lot because of performance which becomes the baton to guide teachers' academic activities. According to the interviews in the four universities, they adopt a trend prediction method to formulate the appraisal standard of scientific research, and confirm tasks in the appraisal period according to average output of teachers' scientific researches three years ago $(2009,2010$ and 2011). So when teachers make the second cognitive appraisal, they can easily draw the conclusion of "jump and get". As a result, the performance appraisal system is a kind of challenging stress to them. Some teachers in the interviews said that the appraisal system is related to their job, and nobody dares to ignore it. And as long as they work hard, teachers can finish the task. When this kind of challenging stress arouses and stimulates teachers' scientific research enthusiasm and impetus and transforms into academic activities, scientific research achievements will undoubtedly increase in both quantity and quality. In the same token, the emphasis on the quality in the performance appraisal system also makes teachers work hard to improve the research level.

Secondly, the system has different stimulating functions as to professors, associate professors, lecturers and teaching assistants. The data show that functions of the performance appraisal system for professors, associate professors, lecturers and teaching assistants can be divided into three types according to the quantity and quality. First, the quantity and quality do not change significantly, and teaching assistants are representatives of this type. Of the investigated 28 teaching assistants, most of them are art teachers although there are many other related professions. In addition, these teachers are mainly Masters, and few of them are Bachelors. Second, the quantity and quality change significantly, and lecturers are representatives of this 
type. In this study, the quantity of lecturers' articles published in core journals has a significant difference before and after the implementation of the system. Third, there is no significant increase in the quantity, but the quality is improved significantly, and professors and associate professors are representatives of this type. However, the mean deviation of the number of professors' articles published in core journals is greater than that of associate professors' articles before and after implementing the system, which shows that professors pay more attention to publishing high-quality articles than associate professors.

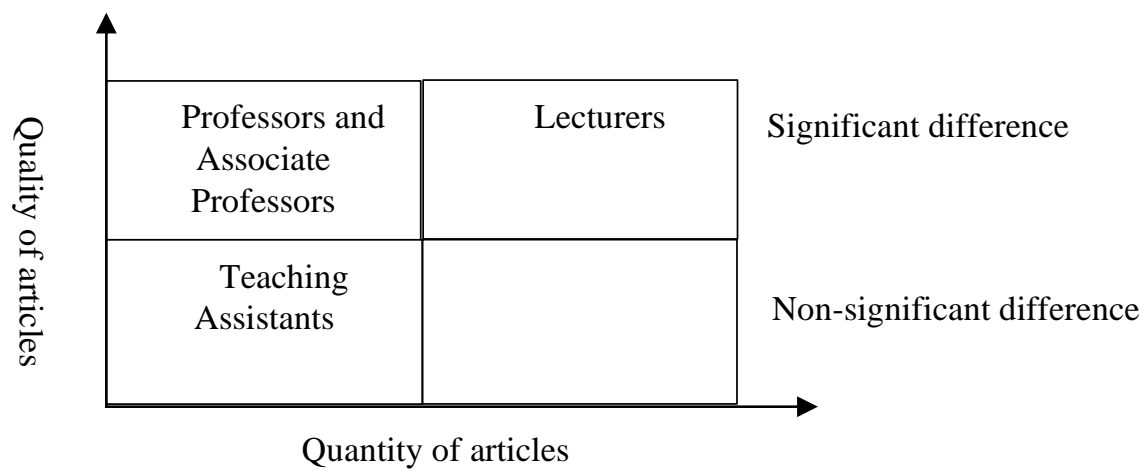

Fig. 1. Scientific changes of professors, associate professors, lecturers and teaching assistants

Human capital stock lifecycle theory points out that with the advance of time and aging, the increase in human capital stock is significant and persistent, and the personal working efficiency and ability is relatively high with the increase in marginal output [1]. For a teacher, when he just enters the academic field, he is in the starting point or the bottom of the profession (teaching assistants). With the growth of the age, scientific knowledge is accumulated day by day with higher academic achievements, and then he will be promoted to a new position (lecturer). When the process is repeated twice, he will reach the peak of his career (professor). This also means that when a teacher is promoted, his academic ability must be improved than ever. Human capital stock lifecycle theory explains the relationship between one's ability and age and reveals a diachronic and vertical relationship. But if the samples of the study are large enough, the theory is also applicable to the analysis of the cross-sectional data, namely the differences in the ability of teaching assistants, lecturers, associate professors, and professors. Obviously, due to the lack of accumulation, the ability of teaching assistants is the lowest of the four groups. The relevant data show that the teaching time of the 28 teaching assistants is seven years on average and they are mainly Masters. According to the appraisal documents of position titles of the sample universities, Masters will automatically improve as teaching assistants after working one year, and they have qualifications to become lecturers after two years. The main reason why they are still teaching assistants is that their academic ability is not enough. Therefore, even if there is a stress of performance appraisal, for them, "the 
spirit is good, but the flesh is weak". For them, the system is not a challenging stress but an obstacle stress, thus their research performance has no significant difference before and after the implementation of the system. Some of the lecturers have a Doctor's degree, and the rest are promoted from a teaching assistant. For teachers with a Doctor's degree, the strict academic discipline in the period of doctoral study makes them develop a good scientific research quality. Topics of doctoral dissertation under the guidance of the doctoral supervisor make their research become the academic front, and their abundant energy and enthusiasm in academic exploration make the performance appraisal system a challenging stress. So they improve their scientific research productivity and influence at the same time. For other lecturers promoted from teaching assistants, the performance appraisal system is also a challenging stress because they gradually accumulate some experience in scientific research and improve the ability of scientific research on the academic road. For associate professors and professors, especially professors, they have reached the top of the career ladder and their salary can meet the basic survival needs, so they begin to pursue the sense of self value and professional achievements. The specific presentation form is to obtain higher academic prestige for the origin of the university is the community of scholars composed by scholars with high academic prestige and followers. The scholars with a high academic prestige are prototypes of university teachers [13], High academic prestige is the indispensable quality and fundamental characteristic of teachers. Academic people have already formed a consensus that different levels of performance cannot be replaced, namely accumulation of performance of teachers at the low level can never replace a high level of performance [14]. An article of high level can give teachers far more peer recognition and self-satisfaction than ten articles of low level. Some professors in the interviews point out those articles of high level contribute to improving academic prestige, while those of low level are harmful to academic prestige. Writing articles of high level takes time because soft fire makes sweet malt. Therefore, although the performance appraisal system is implemented, they stick to academic quality, which makes them give no attention to the quantity but the quality of articles.

\section{Conclusion}

The validity of the system is different with the different stimulating and restraining subjects. Generally speaking, teachers from research universities in China are in a good academic atmosphere, have higher academic capital, stress on and pursue academic prestige, and their academic discipline and awareness make them believe that their soul and destiny depend on whether he can make certain achievements in academic researches. The full mobilization of internal motivation makes the external performance appraisal system useless. However, teachers in research-teaching universities and teaching universities are mainly responsible for the heavy teaching tasks. Their relatively low cultural and social capital, and academic platform and scientific research conditions in universities, make it difficult for them to have an strange "euphoria" which is sniffy in the eyes of the outsiders and an ambition of 
"thousands of years has passed before you come, and thousands of years in the future is waiting in silence" [8]. Academic activity is just a "vocation" for them to make a living rather than an "career". The lack of internal motivation needs the stimulation and restraint of the external system. Therefore, the performance appraisal system plays a certain role in stimulating teachers in research-teaching universities and teaching universities.

The present study has found that the performance appraisal system is a challenging stress for teachers in research-teaching universities and teaching universities in China which motivates teachers to improve their productivity and influence of scientific researches and has a positive influence on academics, so it is reasonable and necessary. At the same time, due to different scientific research abilities and career pursuits of professors, associate professors, lecturers and teaching assistants, the performance appraisal system has different influences on them: the scientific research influence of professors and associate professors has improved significantly, while their productivity has changed slightly; the productivity and influence of scientific research of lecturers have significantly improved; those of teaching assistants have not changes significantly. The conclusion offers the following suggestions for the improvement of the performance appraisal system: different appraisal indexes can be created according to different groups of teachers, such as designing the appraisal index of "quality of scientific researches" for professors and associate professors and the index of "both quantity and quality of scientific researches" for lecturers and no appraisal for teaching assistants.

The innovation of the study lies in the application of empirical methods to analyze teachers' performance appraisal system in research-teaching universities and teaching universities in China at the global level, using challenging stress theory to reveal the internal mechanism of the performance appraisal system for teachers instead of human and social capital theory used in existing literatures. The limitation is that the scope of the dependent variable is narrow, in that only the variable "article" is used to represent teachers abilities of scientific research. In fact, scientific projects, especially national projects can better manifest teachers' scientific research ability, and the narrowed independent variable may bring certain influence to the conclusion. Subsequent research will add more dependent variables to further test the reliability of the conclusion.

Acknowledgements. National social science foundation program: the faculty' performance appraisal system basing on stakeholder perspective(BFA140042)

\section{References}

1. Becher, G. S.: The Economic Approach to Human Behaviour. Chicago: University of Chicago Press, p. 86 (1976).

2. Cai Chengping: The performance gets Chinese enterprises into trouble, http://finance.sina.com.cn/zl/ international/20160113/092724150036.shtml, last accessed $2017 / 10 / 25$ 
3. Cavanaugh, M A, Boswell, W. R, Roehing, M. V. et al. : An empirical examination of selfreported work stress among U.S. management. Journal of Applied Psychology, 85(1), pp. 65-74, (2000).

4. Chen Tingzhu: The ideal of universities: value orientation and its position and limit $[\mathrm{M}]$. Qingdao: China Ocean University Press, p. 166, (2008).

5. Folkman S, Lazarus R S.: If it changes it must be a process: Study of emotion and coping during three stages of a college examination. Journal of Personality and Social Psychology, 48(1), pp. 150-170, 160-165, (1985).

6. Lazarus, R. S.: Psychological stress in the workplace. Journal of Social Behavior \& Personality, 6(7), pp.1-13, (1991).

7. Liu Dege, Shi Kan, Wang Yongli, Gong Hui: The relationship between challengingobstacle stress source, job involvement and satisfaction. Journal of Management Science, (02), pp.2-3, (2011)

8. Weber, M.: Academics and politics. Translated by Qian Yongxiang et al. Guilin: Guangxi Normal University Press, p. 166, (2004).

9. Shi Yu, Liu Cong, Liu Xiaoqian, Shi Kan: The research overview of working stress. Research on Economics and Management, (04), pp. 101-107, (2004).

10. Wang Huanan, Bao Haiqi:. The system analysis of "quantitative appraisal" in the management of university teachers [J]. Education Review,2010(06):55

11. Yin Jingong, Wang Yingluo: Alternative empirical research on teaching and scientific research performance in the appraisal of professional titles. Science Research Management, (03), p. 152, (2005).

12. Zhang Guanglei, Liao Jianqiao, Jin Xin: Social capital, academic rent seeking and tenure system: a study on the mode of appointment system of university scientific researchers. Journal of Higher Education, (12), p. 29, (2008).

13. Zhang Yingqiang: The social roles, responsibilities and missions of university teachers. Tsinghua Journal of Education, (01), p. 9, (2009).

14. Zhao Shusong, Liao Jianqiao: Comparative analysis of the theoretical model of the appraisal of the technical position of the teachers in universities. Journal of Higher Education, (04), p.49, (2010).

15. Zhao Yingchuan: Research on university teachers' allowance system in China. Qingdao: China Ocean University Press, p. 167, (2011).ple Heading (Third Level). 